\title{
Optimization of Drawbead Resistance Based on Orthogonal Experiment
}

\author{
Minghe Zhang ${ }^{a}$, Lianfa Yang ${ }^{\mathrm{b}}$ * \\ School of Mechanical \& Electrical Engineering, Guilin University of Electronic Technology, \\ Guilin, Guangxi, 541004, China \\ aMinghezhang126@126.com, by-lianfa@163.com
}

\begin{abstract}
Key words: Automobile panel, Orthogonal experiment, Drawbead resistance coefficient, Forming quality, Weighting coefficient.

Abstract. The impact of drawbead resistances on the stamping process of an automobile panel was investigated based on orthogonal experiment. Simulations based on Dynaform were conducted and two optimal objects that the maximum ratio of thickness reduction (MRTR) and average thickness in deformation region (ATDR) are extracted from simulation results. Optimal drawbead resistances in different weighting coefficients of the two objects have been found. Appropriate weighting coefficients are obtained by verification simulations. The results provide guidance to the practical fabrication.
\end{abstract}

\section{Introduction}

Automobile panel stamping is a typical deep drawing process. Many process parameters influence the product quality greatly [1]. Wrinkling, spring back and rupture are the main defects of automobile cover panels. So as to resolve the problem, drawbeads are widely applied in practical producing. In many cases, whether drawbeads setting is suitable or not determines the feasibility of the stamping process. The method "trial and error" is often used in practical producing, which needs repeated reparation and test, thus greatly increases the fabricating cost [2].

In the finite element analysis (FEA), if geometric drawbeads are adopted, there will be an complex task of drawbeads modeling and meshing. FEA solving time will increase significantly. Equivalent drawbeads are applied extensively in mainstream CAE software. Schematic drawing of a semicircular drawbead provided by Dynaform is shown in Fig. 1. Geometric drawbead models can be determined by equivalent drawbeads. When the required resistances are extremely large, multiple parallel drawbeads are set.

Drawbead resistances behavior of a wheel fender based on Dynaform was investigated in this paper. Different drawbead resistances set were tested in the orthogonal experiment, and two optimal objects MTRT (represented by $a$ ) and ATDR (represented by $t$ ) were selected to evaluate the forming quality. Optimal drawbead coefficients sets in different weighting coefficients of the two objects have been found and then validated on Dynaform. The results provide guidance to practical engineering application.

\section{FEA Simulation Models}

The material of the automobile panel is DQSK36 and the blank thickness is $0.7 \mathrm{~mm}$. Material models are established based on the Barlat (1989) yield function [3]. BT (Belytschko-Tsay) shell elements are adopted to mash the blank, die, punch and blank holder as shown in Fig. 2. Mechanical properties of the material are shown in Table 1. A typical forming process is blanking-drawing-trimming-reshaping. Spring back is not considered as there is a final reshaping 
process. Equivalent drawbeads are divided into 12 sections in drawing. Drawbead resistance coefficients are set respectively. Basic resistances are forces calculated automatically when the blank is locked completely [4]. Other parameters are set automatically in Dynaform.

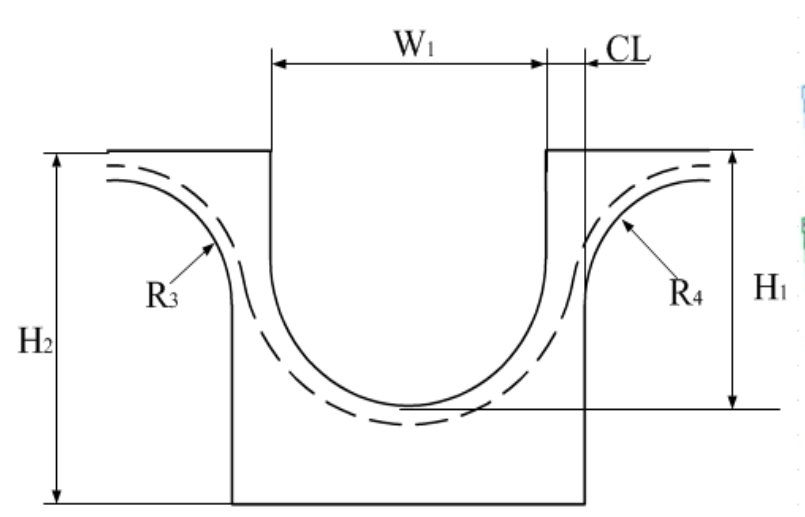

Fig. 1 Schematic drawing of a semicircular drawbead

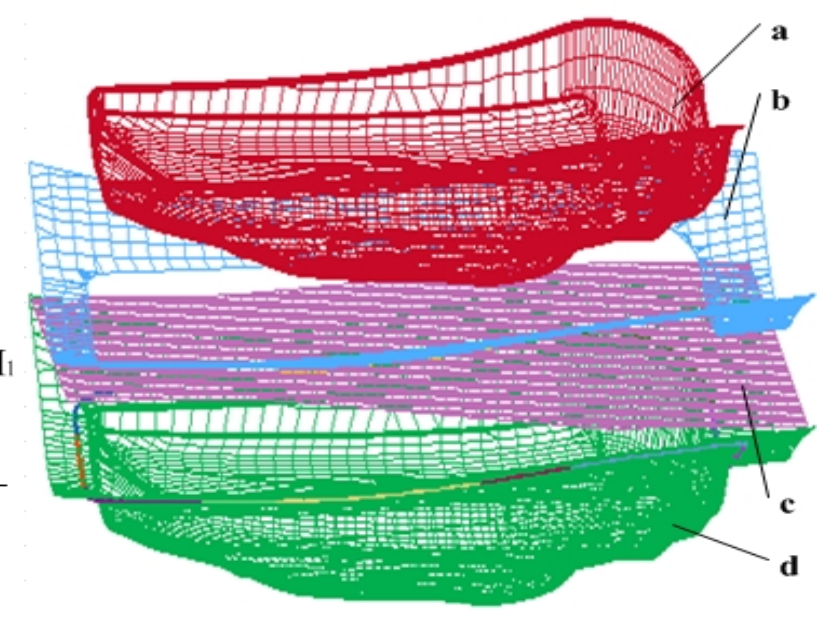

Fig. 2 Finite element models (a) punch, (b) binder, (c) blank, (d) die

Table 1 Mechanical properties of DQSK36.

\begin{tabular}{|c|c|c|c|c|c|c|c|}
\hline \multirow{2}{*}{$\begin{array}{l}\text { Density } \\
\left(\mathrm{t} \cdot \mathrm{mm}^{3}\right)\end{array}$} & \multirow{2}{*}{$\begin{array}{c}\text { Elastic } \\
\text { modulus } \\
(\mathrm{MPa})\end{array}$} & \multirow{2}{*}{$\begin{array}{l}\text { Poisson } \\
\text { ratio }\end{array}$} & \multirow{2}{*}{$\begin{array}{c}\text { Intensity } \\
\text { coefficient } \\
k(\mathrm{MPa})\end{array}$} & \multirow{2}{*}{$\begin{array}{c}\text { Harding } \\
\text { Index } \\
n \\
\end{array}$} & \multicolumn{3}{|c|}{$\begin{array}{l}\text { Anisotropy } \\
\text { coefficient } r\end{array}$} \\
\hline & & & & & $r_{0}$ & $r_{45}$ & $r_{90}$ \\
\hline $7.85 \mathrm{e}-9$ & $2.07 \mathrm{e}-5$ & 0.28 & 520.4 & 0.232 & 1.73 & 1.35 & 2.18 \\
\hline
\end{tabular}

\section{The Design of Orthogonal Experiment}

In the orthogonal experiment, 12 drawbead resistance coefficients are set as 12 factors. The basic level 2 is based on previous experience of similar process. Drawbeads are set end to end, thus avoiding the edge-effects. Factor levels are shown in Table 2. An orthogonal table $\mathrm{L}_{27}\left(3^{12}\right)$ is used to design the orthogonal experiment.

Table 2 Values of factor and level used in orthogonal design.

\begin{tabular}{ccccccccccccc}
\hline \multirow{2}{*}{ level } & \multicolumn{10}{c}{ Drawbead resistance coefficient $(\%)$} \\
\cline { 2 - 13 } & 1 & 2 & 3 & 4 & 5 & 6 & 7 & 8 & 9 & 10 & 11 & 12 \\
\hline 1 & 35 & 40 & 35 & 30 & 40 & 10 & 15 & 60 & 55 & 30 & 40 & 25 \\
2 & 45 & 50 & 45 & 40 & 50 & 20 & 25 & 70 & 65 & 40 & 50 & 35 \\
3 & 55 & 60 & 55 & 50 & 60 & 30 & 35 & 80 & 75 & 50 & 60 & 45 \\
\hline
\end{tabular}

\section{Data Analysis \& Simulation Results}

The experiment result is shown in Table 3. For a multi-objective optimization, there will be a transformation into single-objective optimization, and establishment of a comprehensive evaluation. Therefore, two objects are mapped to a numerical scores range [0,100] [5]. The proper reduction of thickness is generally considered to be from $2 \%$ to $30 \%$, so the proper ARTR in this case is from 0.4900 to 0.6860 . A synthetic weighted mark method was adopted to evaluate the experimental data. The overall indicator $q$ is calculated by Eq. 1 . 
Where $\mu_{1}$ and $y_{1}$ are the weighting coefficient and mapping value of MTRT and $\mu_{2}, y_{2}$ are the weighting coefficient and mapping value of ATDR.

Meanwhile, there is a relation between $\mu_{1}$ and $\mu_{2}$ in Eq. 2 .

$\mu_{1}+\mu_{2}=1$

Mapping values $y_{1}$ and $y_{2}$ are calculated respectively by Eq. 3 and Eq. 4.

$\mathrm{y} 1=-357.14 \mathrm{a}+107.14$,

$\mathrm{y} 2=510.20 \mathrm{t}-250.00$.

When $\mu_{1}, \mu_{2}$ are in different value, optimal coefficients of drawbead resistance obtained by Eq. 1 are shown in Table 4.

Table 3 Orthogonal experiment results.

\begin{tabular}{cccccccccccccccc}
\hline & & & & \multicolumn{1}{c}{ Fest } & \multicolumn{1}{c}{ Terctors } & & & & & & MTRT & $\begin{array}{c}\text { ATDR } \\
(\%)\end{array}$ & $(\mathrm{mm})$ \\
\hline 1 & 35 & 40 & 35 & 30 & 40 & 10 & 15 & 60 & 55 & 30 & 40 & 25 & 30.9414 & 0.6608 \\
2 & 35 & 40 & 35 & 30 & 50 & 20 & 25 & 70 & 65 & 40 & 50 & 35 & 34.6436 & 0.6473 \\
3 & 35 & 40 & 35 & 30 & 60 & 30 & 35 & 80 & 75 & 50 & 60 & 45 & 67.7245 & 0.6269 \\
4 & 35 & 50 & 45 & 40 & 40 & 10 & 15 & 70 & 65 & 40 & 60 & 45 & 47.3406 & 0.6462 \\
5 & 35 & 50 & 45 & 40 & 50 & 20 & 25 & 80 & 75 & 50 & 40 & 25 & 60.2538 & 0.6379 \\
6 & 35 & 50 & 45 & 40 & 60 & 30 & 35 & 60 & 55 & 30 & 50 & 35 & 76.9011 & 0.6358 \\
7 & 35 & 60 & 55 & 50 & 40 & 10 & 15 & 80 & 75 & 50 & 50 & 35 & 58.5451 & 0.6359 \\
8 & 35 & 60 & 55 & 50 & 50 & 20 & 25 & 60 & 55 & 30 & 60 & 45 & 45.0074 & 0.6374 \\
9 & 35 & 60 & 55 & 50 & 60 & 30 & 35 & 70 & 65 & 40 & 40 & 25 & 80.3156 & 0.6265 \\
10 & 45 & 40 & 45 & 50 & 40 & 20 & 35 & 60 & 65 & 50 & 40 & 35 & 64.6967 & 0.6447 \\
11 & 45 & 40 & 45 & 50 & 50 & 30 & 15 & 70 & 75 & 30 & 50 & 45 & 55.9325 & 0.6412 \\
12 & 45 & 40 & 45 & 50 & 60 & 10 & 25 & 80 & 55 & 40 & 60 & 25 & 80.9712 & 0.6335 \\
13 & 45 & 50 & 55 & 30 & 40 & 20 & 35 & 70 & 75 & 30 & 60 & 25 & 61.0946 & 0.6423 \\
14 & 45 & 50 & 55 & 30 & 50 & 30 & 15 & 80 & 55 & 40 & 40 & 35 & 34.4612 & 0.6441 \\
15 & 45 & 50 & 55 & 30 & 60 & 10 & 25 & 60 & 65 & 50 & 50 & 45 & 47.7795 & 0.6404 \\
16 & 45 & 60 & 35 & 40 & 40 & 20 & 35 & 80 & 55 & 40 & 50 & 45 & 66.5534 & 0.6343 \\
17 & 45 & 60 & 35 & 40 & 50 & 30 & 15 & 60 & 65 & 50 & 60 & 25 & 47.6287 & 0.6412 \\
18 & 45 & 60 & 35 & 40 & 60 & 10 & 25 & 70 & 75 & 30 & 40 & 35 & 75.3569 & 0.6363 \\
19 & 55 & 40 & 55 & 40 & 40 & 30 & 25 & 60 & 75 & 40 & 40 & 45 & 46.4354 & 0.6461 \\
20 & 55 & 40 & 55 & 40 & 50 & 10 & 35 & 70 & 55 & 50 & 50 & 25 & 54.0149 & 0.6412 \\
21 & 55 & 40 & 55 & 40 & 60 & 20 & 15 & 80 & 65 & 30 & 60 & 35 & 71.7069 & 0.6351 \\
22 & 55 & 50 & 35 & 50 & 40 & 30 & 25 & 70 & 55 & 50 & 60 & 35 & 41.0041 & 0.6409 \\
23 & 55 & 50 & 35 & 50 & 50 & 10 & 35 & 80 & 65 & 30 & 40 & 45 & 64.5327 & 0.6332 \\
24 & 55 & 50 & 35 & 50 & 60 & 20 & 15 & 60 & 75 & 40 & 50 & 25 & 78.4393 & 0.6391 \\
25 & 55 & 60 & 45 & 30 & 40 & 30 & 25 & 80 & 65 & 30 & 50 & 25 & 36.8041 & 0.6395 \\
26 & 55 & 60 & 45 & 30 & 50 & 10 & 35 & 60 & 75 & 40 & 60 & 35 & 58.7977 & 0.6387 \\
27 & 55 & 60 & 45 & 30 & 60 & 20 & 15 & 70 & 55 & 50 & 40 & 45 & 49.9884 & 0.6398 \\
\hline
\end{tabular}


Table 4 Optimal drawbead resistances in different weighting coefficient of MRTR and ATDR

\begin{tabular}{ccccccccccccc}
\hline & \multicolumn{10}{c}{ Optimal drawbeads resistance coefficient level } \\
\cline { 2 - 12 } & 1 & 2 & 3 & 4 & 5 & 6 & 7 & 8 & 9 & 10 & 11 & 12 \\
\hline 0.9 & 1 & 1 & 3 & 1 & 1 & 3 & 2 & 1 & 1 & 3 & 1 & 3 \\
0.8 & 1 & 1 & 3 & 1 & 1 & 3 & 2 & 1 & 1 & 3 & 1 & 3 \\
0.7 & 1 & 1 & 3 & 1 & 1 & 3 & 2 & 1 & 1 & 3 & 1 & 3 \\
0.6 & 1 & 1 & 3 & 1 & 1 & 3 & 2 & 1 & 1 & 3 & 1 & 3 \\
0.5 & 1 & 1 & 3 & 1 & 1 & 3 & 2 & 1 & 1 & 3 & 1 & 3 \\
0.4 & 1 & 1 & 3 & 1 & 1 & 3 & 1 & 1 & 1 & 3 & 1 & 3 \\
0.3 & 1 & 1 & 3 & 1 & 1 & 3 & 1 & 1 & 1 & 3 & 1 & 3 \\
0.2 & 1 & 1 & 3 & 1 & 1 & 3 & 1 & 1 & 1 & 3 & 1 & 3 \\
0.1 & 1 & 1 & 1 & 1 & 1 & 1 & 1 & 1 & 1 & 3 & 1 & 3 \\
\hline
\end{tabular}

Verification experiments were conducted and results are shown in Table 5. From Table 5 we can conclude that the proper weighting coefficients range of $\mu_{1}$ in this case is likely to be $[0.2,0.4]$.

Table 5 Verification results of different weighting coefficient.

\begin{tabular}{cccccccccc}
\hline$\mu_{1}$ & 0.9 & 0.8 & 0.7 & 0.6 & 0.5 & 0.4 & 0.3 & 0.2 & 0.1 \\
\hline$a(\%)$ & 35.530 & 35.530 & 35.530 & 35.530 & 35.530 & 29.9252 & 29.9252 & 29.9252 & 30.6460 \\
$t(\mathrm{~mm})$ & 6.6710 & 6.6710 & 6.6710 & 6.6710 & 6.6710 & 6.6581 & 6.6581 & 6.6581 & 6.6582 \\
\hline
\end{tabular}

\section{Conclusions}

No significant variations of MRTR are observed in different drawbead resistances, but variations of ATDR are remarkable. A feasible method based on orthogonal experiment is proposed for multi-objective optimization about drawbeads in metal sheet forming. Proper weighting coefficients of MRTR and ATDR are found, which provides guidance to the practical fabrication.

\section{Acknowledgments}

The authors gratefully acknowledge the support of the Guangxi Natural Science Foundation (grant number 2013GXNSFAA019305) and Guangxi Key Laboratory of manufacturing System \& Advanced Manufacturing Technology (grant number 14-045-15-005Z).

\section{References}

[1] M.A. Ahmetoglu, G. Kinzel, T. Altan: Journal of Materials Processing Technology. 71 (1997) 147-151 .

[2] L.L. Wang, Y.P. Zheng, G. Yan, Z.G. He: Hot Working Technology. 43 (2014) 142. (In Chinese)

[3] F. Barlat, J. Lian: International Journal of Plasticity. 51 (1989) 51-66 .

[4] W.L. Xu: Journal of Materials Processing Technology. 100 (2000) 219-233.

[5] Y. Li, H.T. Zhang, Y.P. Li: Machine Design and Research, 28 (2012) 92. (In Chinese) 